\title{
Development of Walkability Indicator for Smart Shrinking:
}

\author{
Case Study of Sprawl Areas in Northern Osaka Metropolitan
}

\author{
Haruka Kato ${ }^{1 *}$ and Kiyoko Kanki ${ }^{1}$ \\ 1 Department of Architecture, Kyoto University \\ *Corresponding Author, Email: kato.haruka.52v@st.kyoto-u.ac.jp
}

Received: May 15, 2017; Accepted: July 18, 2019

Key words: Smart Shrinking, Walkability, Sprawl Area, Northern Osaka Metropolitan Area, GIS Analysis, Questionnaire Survey

\begin{abstract}
Urban shrinkage is a problem that is faced by some metropolitan areas globally in urban cities faced with depopulation. Therefore, these cities require "smart shrinking", which consists of design methods intended to satisfy residents' living needs, even though the population is declining. The purpose of this paper is to develop a walkability indicator for visualizing smart shrinking. The methods include statistical analysis by GIS analysis and questionnaire in the Northern Osaka Metropolitan Area where there are many small-sprawl areas. The following four results were identified. First, the population decline in sprawl areas indicates the regional characteristics of each city. Second, this paper develops a walkability indicator composed of household density, convenience of facilities, road connectivity, and traffic safety. Third, Wi(i), which is walkability in each residential area, in sprawl areas, and in public housing areas, is important for future population change. Finally, the validity and effectiveness of the indicator is clarified by questionnaires regarding regional evaluation. In conclusion, the walkability indicator is able to visualize smart shrinking in sprawl areas.
\end{abstract}

\section{INTRODUCTION}

\subsection{Background: Smart Shrinking in Sprawl Areas}

The population density in Japanese Metropolitan Areas increased rapidly over the 50 years following WWII. After this high economic growth period, Japanese academic researchers have evaluated the areas as problematic from the perspective of efficient land use and transportation (Kurokawa et al., 1995; Tsukaguchi, 1991). Based on these factors an evaluation by the Japanese central government was facilitated to influence policies for renovating the areas with sufficient infrastructure. A policy on land readjustment was created to this effect, together with implementing wider roads with sidewalks and high-rise buildings that can withstand disasters (Sorensen, Andre, 1999).

However, after 2010, the population began to decline in Japan, forcing the central government to create a policy of "Japanese Compact Cities", which promotes the renovation of some sprawl areas with sufficient infrastructure (Hattori, Kaido, \& Matsuyuki, 2017). The policy forced local governments to renovate the sprawl are as quickly as there was also speculation by the central 
government that the population would decline rapidly (Japanese MLIT (Ministry of Land, Infrastructure and Transport), 2015). However, according to NIPSSR Tokyo (National Institute of Population and Social Security Research Tokyo) (2013), it is estimated that the population will decline gradually by $5.18 \%$ from 2015 to 2035 , and not rapidly.

Therefore, the changes in the policies did not align with priorities in the local government, and the local governments want to evaluate the existing infrastructure from the residents' point of view by conducting a regional evaluation. However, residents have to assess the areas and have deemed it comfortable to live in narrower streets without cars (Hibata, Asami, \& Endo, 2009). For local governments, modification of the infrastructure was not the priority in the policy-making compared to the welfare regarding medicine and childcare (Japanese MIC (Ministry of Internal Affairs and Communications), 2016). Therefore, local governments do not have to renovate the sprawl areas with sufficient infrastructure following the central government policy, if the lack of infrastructure is evaluated as not a problem from the viewpoint of residents' regional evaluation.

To solve this contradiction of the evaluation on infrastructure, the basic concept of Japanese urban policy must change from a population growthcentred approach to a declining-centred approach (Oswalt, 2006). In other words, the policy for sprawl areas should change from "Japanese Compact Cities" to "Smart Shrinking" (Figure 1). For smart shrinking, it is important for a place-based approach to utilize existing narrower streets, vacant houses, and open spaces efficiently (Hollander, Justin B et al., 2009). It is also important for a social approach to incorporate with the various communities (Hollander, Justin B. \& Németh, 2011). In addition, it is necessary that local governments plan policies for the areas based on residents' regional evaluation, because of recommended place-based and social approaches (Wiechmann \& Pallagst, 2012). Based on these points, this paper defines the concept of smart shrinking as "design methods intended to satisfy residents' living needs, even though the population is declining". Therefore, the key point to plan a policy for smart shrinking is to analyse integral diverse scales - ranging from the personal scale for monitoring residents' living needs, to the metropolitan scale for planning urban policy.

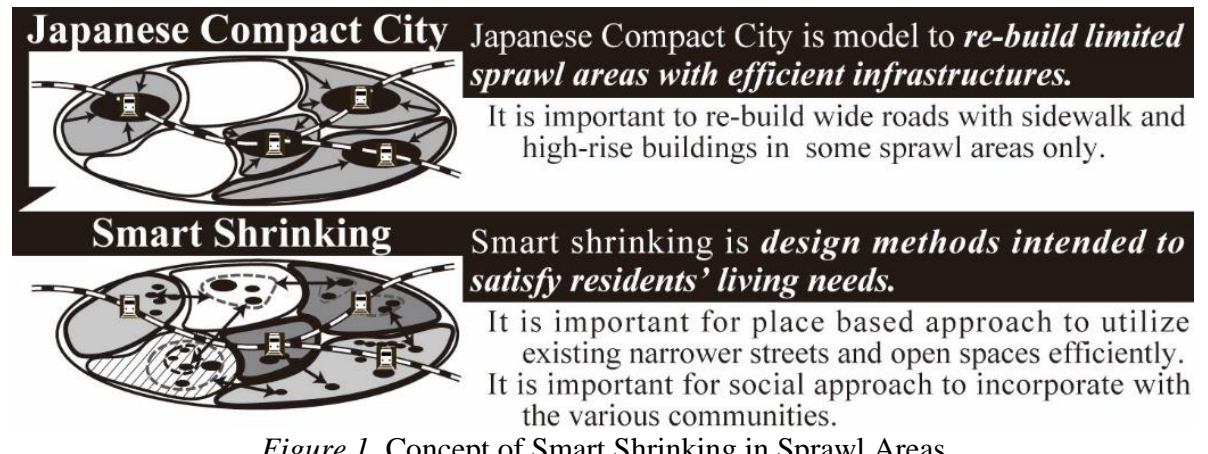

\subsection{Aim: Development of Walkability Indicator}

The aim of this paper is to develop an indicator for visualizing smart shrinking in sprawl areas from the perspective of residents' regional evaluation as the first step to planning policies for smart shrinking. Therefore, this paper focuses on the concept of "walkability" based on the human walking experience that includes residents' regional evaluations, which consider 
comfortability and sociality. The concept of walkability is easier to understand than accessibility calculated from distances and road shapes because it has a subjective value. In fact, Hanibuchi et al. (2012) clarified that walkability is high in the sprawl areas as they were developed from the 1960s to1980s.

This research surveyed the Northern Osaka Metropolitan Area in Japan. The Northern Osaka Metropolitan Area has many small-sprawl areas that spread independently between the 1950s and 1980s, because of the transformation of rice fields in the absence of efficient urban policies (Sorensen, André, 2001). Therefore, the sprawl areas lack sufficient infrastructure. For example, there are narrow streets with complicated irregular networks, small wooden houses that are weakened from disasters, and irregular open spaces in which it is difficult to build anything (Figure 2).

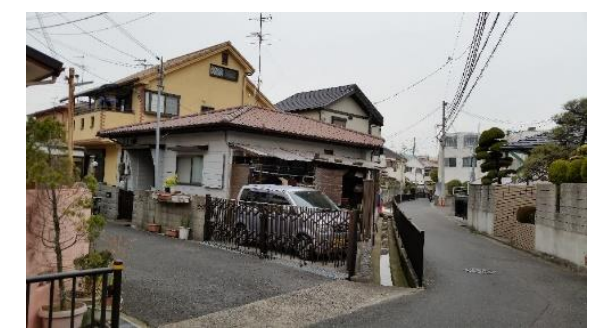

Figure 2. Picture of sprawl areas in Northern Osaka Metropolitan Area

There has been previous research carried out in developing walkability indicators, highlighted in the next sections. This research utilized relevant research methodologies and analyses. The second section begins with the analyses of population decline using statistical analyses of Japanese census data in the study area. The third section introduces the walkability indicator study method implemented for the research site based on previous research. Section four highlights and analyses the validity and effectiveness of the walkability indicator using questionnaire surveys about the regional evaluation for Ibaraki City. The study concludes in the fifth section of this paper.

\subsection{Positioning of Previous Studies}

Previous studies classified indicators for visualizing smart shrinking into two categories. The first involves indicators that integrate various factors for monitoring urban sustainability. The second category needs specialized indicators according to one factor for visualizing a sustainable life for residents.

Although there are many indicators for visualizing urban sustainability (e.g. (AtKisson, 1996), there are few for visualizing smart shrinking in Japan. One well-known indicator, "SURQUAS", was developed from a viewpoint of a Triple Bottom Line (Suzuki et al., 2009). Compared to that indicator, the novelty of this paper is to develop a walkability indicator for visualizing sustainable residency.

The public health field has developed walkability indicators. As an example of a well-known walkability indicator, Cerin et al. (2006) developed "ANEWS" (Abbreviated Neighborhood Environment Walkability Scale) for visualizing walkability based on the health of respondents. From the various indicators, Brownson et al. (2009) categorized three types of surveys, including objective surveys based on GIS, subjective surveys based on questionnaires, and observational surveys based on systematic observations. Among the three types, the objective surveys based on GIS are easy for local governments to 
visualize walkability in metropolitan areas by their own data. Thus, this paper develops a walkability indicator based on GIS survey.

Among walkability indicators based on GIS survey, Frank et al. (2005) developed "Walkability Index" for visualizing walkability based on GIS. The novelty of this paper is in the development of the walkability indicator for visualizing not only residents' health for public health purposes but also the sustainability of respondents' lives for smart shrinking.

\section{POPULATION DECLINE IN NORTHERN OSAKA METROPOLITAN AREA}

\subsection{Urbanization of Northern Osaka Metropolitan Area}

The aim of Section 2 is to clarify population decline in the Northern Osaka Metropolitan Area. In city planning, the region is in the North Osaka City planning area. The population is 1.75 million. Moreover, the region has been the main traffic point between Osaka and Kyoto for a long time. This has led to the region's rapid urbanization from the 1950s to 1980s. However, the population has begun to decline nowadays (Buhnik, 2010).

Analyses of aerial photos ${ }^{[1]}$ (Figure 3) verifies the spread of previous urbanization. The white areas show the many small-sprawl areas that have led to the spread of urbanization.
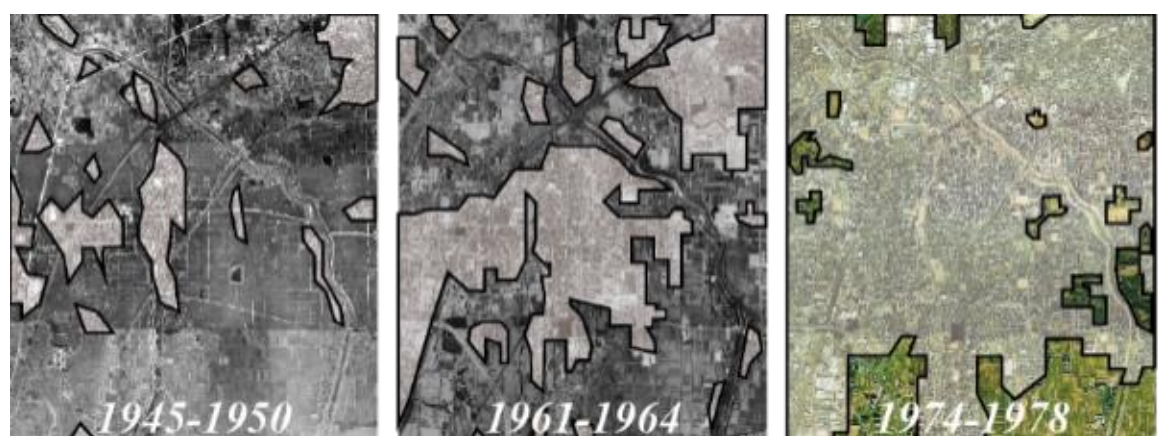

Figure 3. Urbanization areas (White areas) of Northern Osaka Metropolitan Area

\subsection{Category of City Blocks by Statistical Analysis}

Section 2.1 clarified the spread of urbanization with many small-sprawl areas. Section 2.2 aims to clarify the location of sprawl areas using statistical analysis, thus categorizing residential clusters of city blocks. The method implemented in this section is an urban factorial ecological analysis. Using Japanese census data, the analysis consists of five steps.

First, the standardization of 49 indicators for city blocks of the Japanese census in $2010^{[2]}$. Next, principal component analysis is conducted on the standardized composition ratio. Third, categorizing residential clusters by hierarchical cluster analysis using principal component scores is done. From the analysis, thirteen principal components were extracted according to the Guttman Kaiser Criterion. Finally, the characteristics content composition ratio of the clusters (Table 1) was examined.

Table 1 shows that the number of clusters is ten. They are not only sprawl areas but also dense areas, suburban areas, public housing areas, company residential areas and so on. Next, the clusters are mapped ${ }^{[3]}$ (Figure 4). Figure 4 shows the location of residential clusters including sprawl areas. The figure shows that the sum of each residential cluster is high in dense areas, sprawl 
areas, suburban areas, and public housing areas. Thus, section 2.2 compares the locations of four clusters.

Table 1. Content composition ratio of the residential clusters (Cronbach's $\alpha=0.85$ )
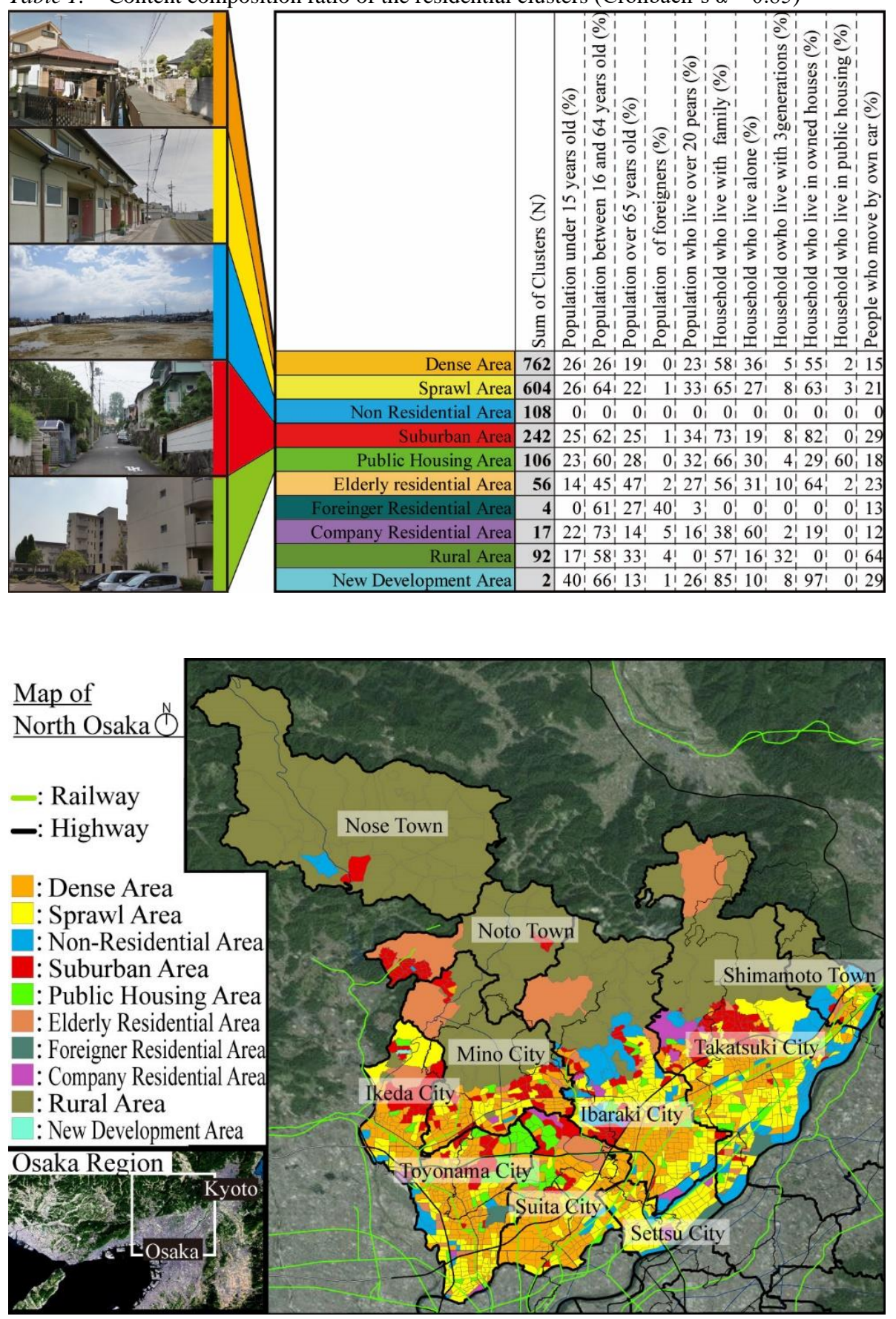

Figure 4. Category of city blocks in Northern Osaka Metropolitan Area

First, dense areas are located along the railways. The area encountered rapid urbanization in the 1950s to the 1980s without enough infrastructure leading to the Japanese central government designating parts of the areas as very susceptible to potential disaster (Japanese MLIT (Ministry of Land, Infrastructure and Transport), 2011).

Second, sprawl areas are located on the outer edges of the dense areas. The areas have not only houses but also farmlands. Like the dense areas, these areas also have urgent issues pertaining to the underdevelopment of sufficient 
infrastructure, because the areas also urbanized separately (Mitani \& Yamanaka, 1992).

Third, suburban areas are located in hilly areas. The areas have problems with the rapid aging of residents. That is because of the heterogeneity of the population composition ratio (Miwa, Yasuda, \& Suekane, 1996).

Finally, in public housing areas, there are many public housings, built by housing departments of local governments and the Urban Renaissance Agency. The area is separately located between dense areas and sprawl areas.

\subsection{Population Decline in the Residential Clusters}

Residential clusters of each city block were identified in Figure 4 by the urban factorial ecological analysis. Section 2.3 aims to clarify the future population declines in each city block in the residential clusters using GIS analysis.

Thus, examining the future population projection of each city block in the residential clusters. For the analysis, the data of the "Future population prediction system in Japan [4]" is used (Inoue, T., 2015). The data provided the population change between 2015 and 2035 calculating $\mathrm{D}_{2035}$ based on the existing data (Formula 1). Moreover, This section analyses the mean (Mp) and standard deviation (SDp) of $\mathrm{D}_{2035}$ for each residential cluster (Figure 5).

Formula 1: $\mathrm{D}_{2035}=\frac{P_{2035}-P_{2015}}{P_{2015}}$

$\mathrm{P}_{2035}=$ Estimated population of $2035^{[1]}$

$\mathrm{P}_{2015}=$ Population of 2015 in Japanese Census in 2015 ${ }^{[2]}$

Figure 5 shows that dense areas may be able to maintain high population density in the future $(\mathrm{Mp}(\mathrm{De})=-0.111 / \mathrm{SDp}(\mathrm{De})=0.040)$. Showing that $\mathrm{D}_{2035}$ are low in suburban areas and public housing areas $(\mathrm{Mp}(\mathrm{Su})=-0.128 /$ $\mathrm{SDp}(\mathrm{Su})=0.057$ and $\mathrm{Mp}(\mathrm{Ph})=-0.133 / \mathrm{SDp}(\mathrm{Ph})=0.030)$.

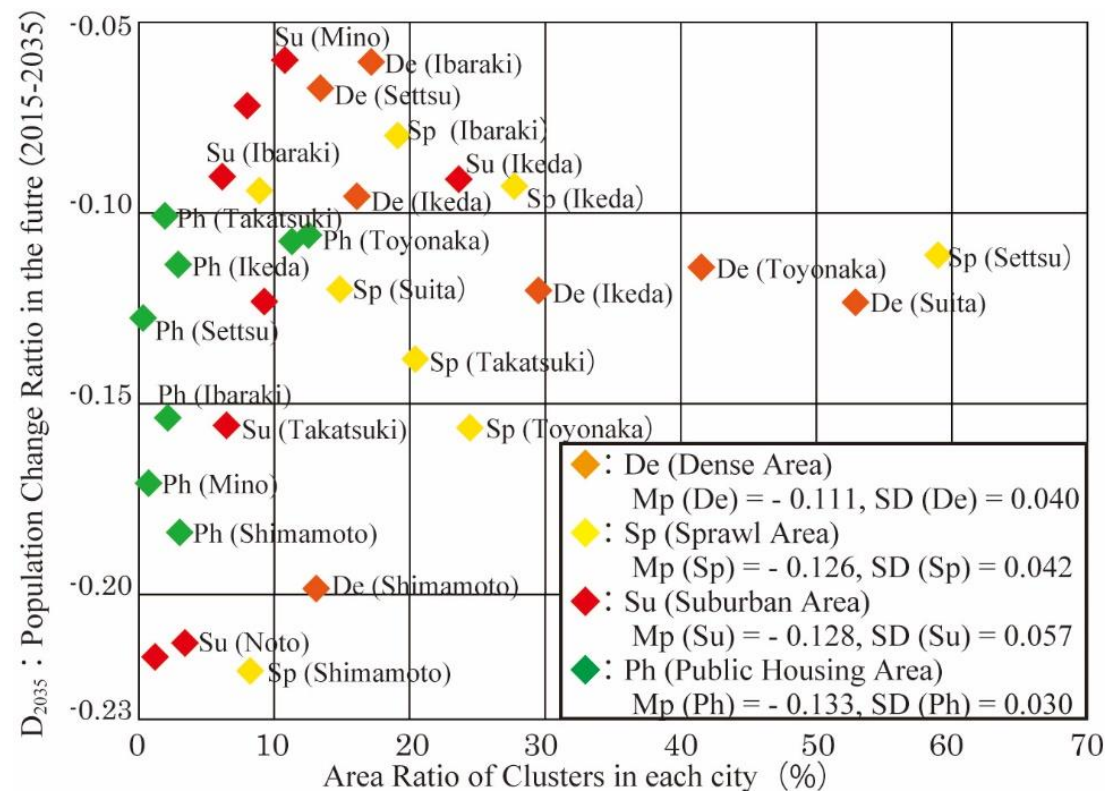

Figure 5. $\mathrm{D}_{2035}$ (Population decline) of each city block in residential clusters.

Finally, Figure 5 also shows that it may be difficult in all sprawl areas to maintain population density in the future $(\mathrm{Mp}(\mathrm{Sp})=-0.126 / \mathrm{SDp}(\mathrm{Sp})=$ 0.042). For example, Ibaraki City has a low area ratio and high $\mathrm{D}_{2035}$, due to 
geographical factors whereby it is sandwiched between mountain and river. However, Shimamoto Town has a low area rate and low $\mathrm{D}_{2035}$, because the town is located furthest from Osaka City.

As a result, Section 2 suggests that population decline in sprawl areas indicates a regional characteristic in cities.

\section{DEVELOPMENT OF WALKABILITY INDICATOR BY LITERATURE REVIEW AND GIS ANALYSES}

\subsection{Defining the Concept of Walkability}

Section 3 aims to develop a walkability indicator for visualizing smart shrinking, "design methods intended to satisfy residents' living needs, even though the population is gradually declining". To this end, Section 3.1 aims to define a concept of walkability from reviewing previous studies.

Walkability is defined as the "Suitable or fit for walking on (of a road, country, etc.,)/ Capability of walking (of a person)" in the Oxford English dictionaries (Simpson \& Weiner, 1989). In previous studies about walkability, the meanings provided are broadly defined. For example, Southworth (2005) defined the concept as "Walkability is the extent to which the built environment supports and encourages walking by providing for pedestrian comfort and safety, connecting people with varied destinations within a reasonable amount of time and effort, and offering visual interest in journeys throughout the network". This suggests that the concept includes not only spatial data but also images of places. Besides this, in the analysis, the concept applies not only to walking but also to cycling (Frank et al., 2006).

As a result, this paper defines the concept of walkability as "relevant to a residential environment that promotes walking or cycling with safety, comfort, and the attractions of daily life."

\subsection{Modelling the Walkability Indicator}

Using the concept of walkability, Section 3.2 aims to model factors and components of the walkability indicator. Based on previous literature, indicators such as Walkability Index (Frank et al., 2005), Walkability 3Ds (Cervero \& Kockelman, 1997), and ANEWS (Cerin et al., 2006), indicator factors were identified by Brownson et al. (2009).

From the 16 factors identified from previous works, four factors were selected from a viewpoint of the concept of walkability. These factors include household density, convenience of facilities, road connectivity and regional safety (Table 2). The selection was based on two reasons. First, they were chosen because of data accessibility by local governments to analyse walkability. For example, the data of household density can be obtained from the web page of Japanese census data "e-Stat", and the data of Regional Safety can be obtained from the web page of the police in each prefecture. Secondly, they are highly reliable factors specified by many indicators. An example of the indicator is ANEWS, which Inoue, S. et al. (2009) verified as being effective in Japan.

As a result, this section models a walkability indicator that consists of four factors (household density, convenience of facilities, road connectivity, and regional safety). 
Table 2. Modelling factors of the Walkability Indicator.

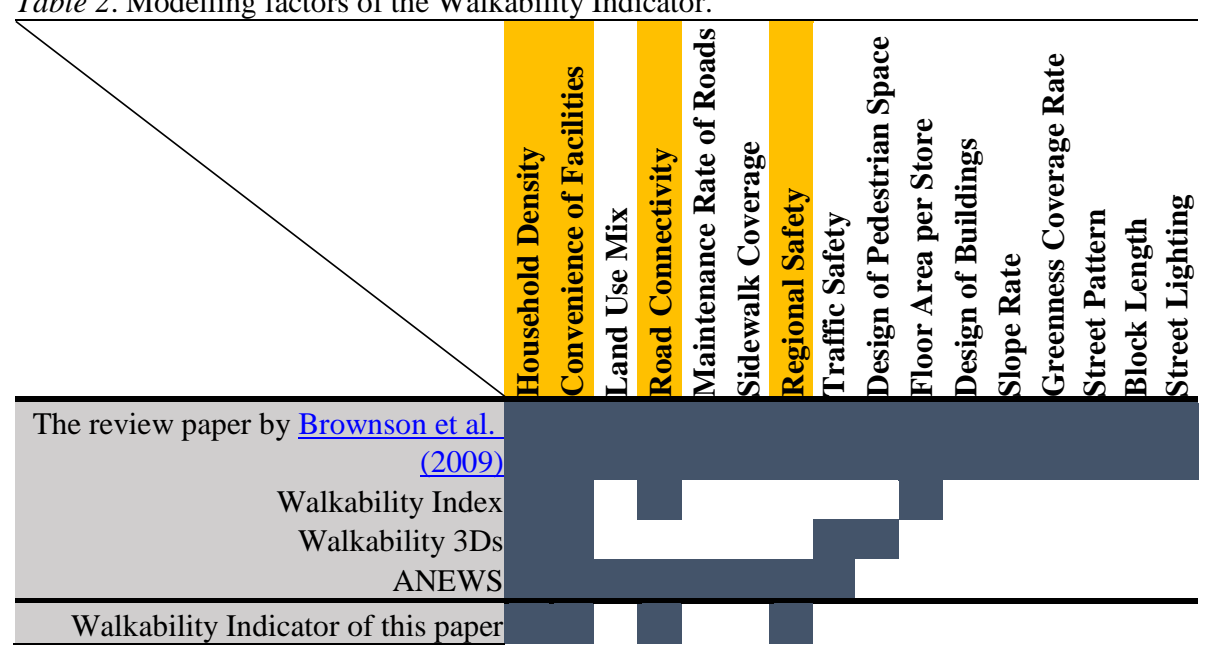

Table 3. Definition and source of components of the Walkability Indicator.

\begin{tabular}{|c|c|}
\hline Component of the indicator & $\mathbf{N}_{\mathrm{k}}(\mathrm{i})$ of each residential area \\
\hline One-storey Houses & Number of One-storey Houses ${ }^{[5]}$ \\
\hline Detached Houses & Number of Detached Houses ${ }^{[5]}$ \\
\hline Apartment Houses & Number of Apartment Houses ${ }^{[5]}$ \\
\hline Commercial facilities & Number of Commercial facilities ${ }^{[6]}$ \\
\hline Medical Facilities & Number of Medical Facilities ${ }^{[6]}$ \\
\hline Educational Facilities & Number of Educational Facilities ${ }^{[6]}$ \\
\hline Nursery Facilities & Number of Nursery Facilities ${ }^{[6]}$ \\
\hline Welfare Facilities & Number of Welfare Facilities ${ }^{[6]}$ \\
\hline Bus Stops & Number of Bus Stops ${ }^{[7]}$ \\
\hline Stations & Number of Stations ${ }^{[7]}$ \\
\hline Roads with $3 \sim 5.5 \mathrm{~m}$ width & Length of Roads with $3 \sim 5.5 \mathrm{~m}$ width $^{[8]}$ \\
\hline Roads with $5.5 \sim 13 \mathrm{~m}$ Width & Length of Roads with $5.5 \sim 13 \mathrm{~m}$ width $^{[8]}$ \\
\hline Roads with $13 \mathrm{~m}$ width & Length of Roads with $13 \mathrm{~m}$ width ${ }^{[8]}$ \\
\hline Places where road robbery occurred & Number of road robbery occurrences ${ }^{[9]}$ \\
\hline Places where children were injured & Number of children injured ${ }^{[9]}$ \\
\hline Places where a traffic accident occurred (cycling) & Number of traffic accidents (cycling) ${ }^{[10]}$ \\
\hline Places where a traffic accident occurred (walking) & Number of traffic accidents (walking) ${ }^{[10]}$ \\
\hline
\end{tabular}

\subsection{Validity of the Walkability Indicator}

Based on the factors identified for walkability indicators in Table 2, Section 3.3 aims to analyse the validity of the walkability indicator.

The method used was structural equation modelling (SEM). Components of the indicator in Table 3 affect the future population of "Future population prediction system in Japan" in each city block (Figure 6). For the analysis, each city block is calculated using the Standard value $F_{k}(i)$ of components of the walkability indicator in Formula 2.

$$
\begin{gathered}
\text { Formula } 2 \ldots \mathrm{F}_{\mathrm{k}}(\mathrm{i})=\frac{C_{k}(\mathrm{i})}{C_{k \max }-C_{k \min }} \\
\mathrm{C}_{\mathrm{k}}(\mathrm{i})=\frac{N_{k}(\mathrm{i})}{\mathrm{A}(\mathrm{i})}
\end{gathered}
$$

$\mathrm{N}_{\mathrm{k}}(\mathrm{i})=$ Number of component $\mathrm{k}$ in each residential area in Table 3

$\mathrm{A}(\mathrm{i})=$ Area of each residential locality

$\mathrm{C}_{\mathrm{kmax}}=$ Maximum value of each $\mathrm{C}_{\mathrm{k}}(\mathrm{i})$

$\mathrm{C}_{\mathrm{kmin}}=$ Minimum value of each $\mathrm{C}_{\mathrm{k}}(\mathrm{i})$ 
Figure 6 shows that reliable results were obtained $(\mathrm{GFI}=0.924 / \mathrm{AGF}=$ 0.880 / RMSEA $=0.075$ ). These results suggest the validity of the walkability indicator.

Moreover, the results clarify the influence on walkability by components of the indicator. For example, Figure 6 shows that "convenience of facilities" has the lowest influence among the walkability indicators (Standardized Estimation Value of "convenience of facilities" $=0.29$ ). Thus, this section analyses the standardized total effect (STE) from component to walkability (Table 4). Table 4 suggests that narrow roads play an important role (STE of "density of roads with $3 \sim 5.5 \mathrm{~m}$ width" $=0.53$, even though STE of "density of roads $13 \mathrm{~m}$ width" $=0.29$ ).

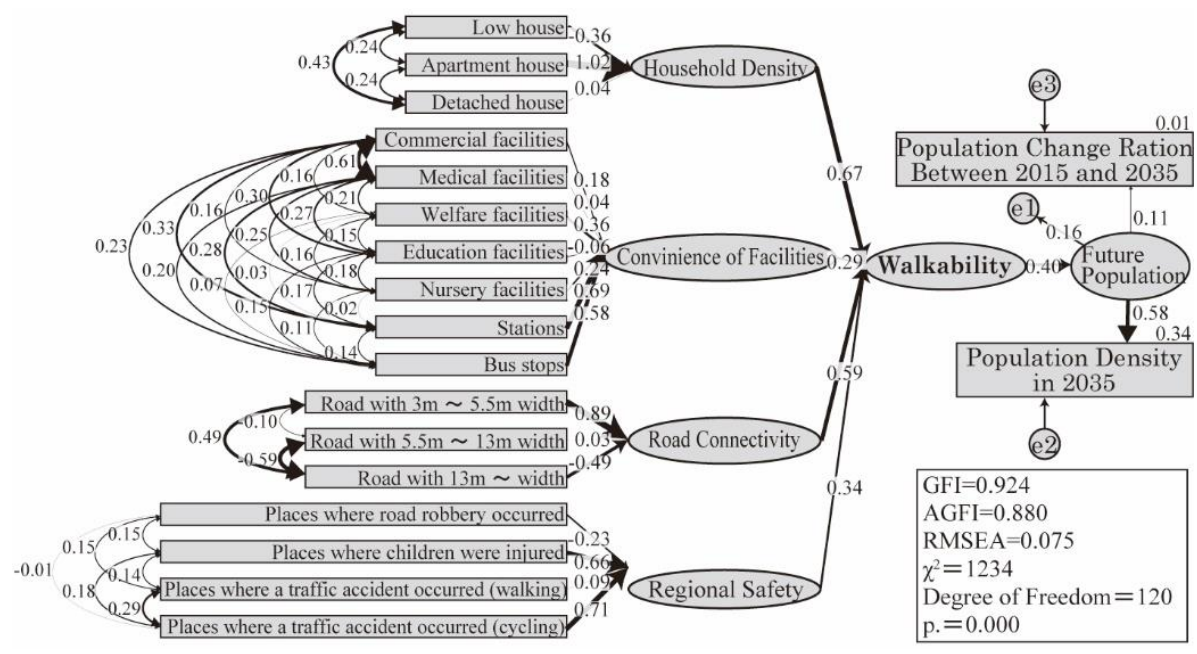

Figure 6. Structural Equation Modelling of the Walkability Indicator

Table 4. Standardized Total Effect of the SEM in Figure 6.

\begin{tabular}{rr} 
& \\
Component "k" of the Indicator & STE \\
\hline Density of Low Houses & -0.24 \\
Density of Detached Houses & 0.02 \\
Density of Apartment Houses & 0.69 \\
Density of Commercial facilities & 0.05 \\
Density of Medical Facilities & 0.01 \\
Density of Educational Facilities & -0.02 \\
Density of Nursery Facilities & 0.07 \\
Density of Welfare Facilities & 0.11 \\
Density of Bus Stops & 0.17 \\
Density of Stations & -0.20 \\
Density of Roads with 3 5.5m width & 0.53 \\
Density of Roads with 5.5 13m width & 0.02 \\
Density of Roads with 13m width & -0.29 \\
\hline Density of Places where Road Robbery Occurred & -0.08 \\
Density of Places where Children were Injured & 0.22 \\
Density of Places where Traffic Accidents Occurred (Cycling) & -0.03 \\
Density of Places where Traffic Accident Occurred (Walking) & 0.24
\end{tabular}

\subsection{Evaluation on Walkability of Each City Block}

\subsubsection{Formulation of the walkability indicator}

The validity of the walkability indicator was clarified by SEM in Figure 6 . Using the walkability indicator in Table 3, Section 3.4 aims to evaluate the walkability of each city block. Thus, Section 3.4 .1 formulates the walkability indicator based on the STE in Table 4 (Formula 3): 
Formula 3: $\quad W_{i}(i)=\sum_{k=0}^{n} a_{k} \times f_{k}(i)$

$a_{k}=$ The STE from component $\mathrm{k}$ to walkability in Table 4 $f_{k}(i)=$ The numerical value of component $k$ of the index

Formula 3 calculated " $\mathrm{W}_{\mathrm{i}}(\mathrm{i})$," which is the walkability of each city block. Next, $\mathrm{W}_{\mathrm{i}}(\mathrm{i})$ was then drawn on the map (Figure 7). The legend in Figure 7 is categorized according to the natural classification. The classification is a method of setting threshold values for the data changes.

As a result, Figure 7 shows that high walkability areas have accumulated in other areas: south of Ibaraki City located along Hankyu Railway Kyoto Line, and the middle of Toyonaka City located along Hankyu Railway Takarazuka Line. Besides this, Figure 7 shows that $\mathrm{W}_{\mathrm{i}}(\mathrm{i})$ is associated not only with geography but also with the residential clusters in Figure 4. In fact, Figure 4 and Figure 7 show that walkability of dense areas is high and walkability of suburban areas are low.

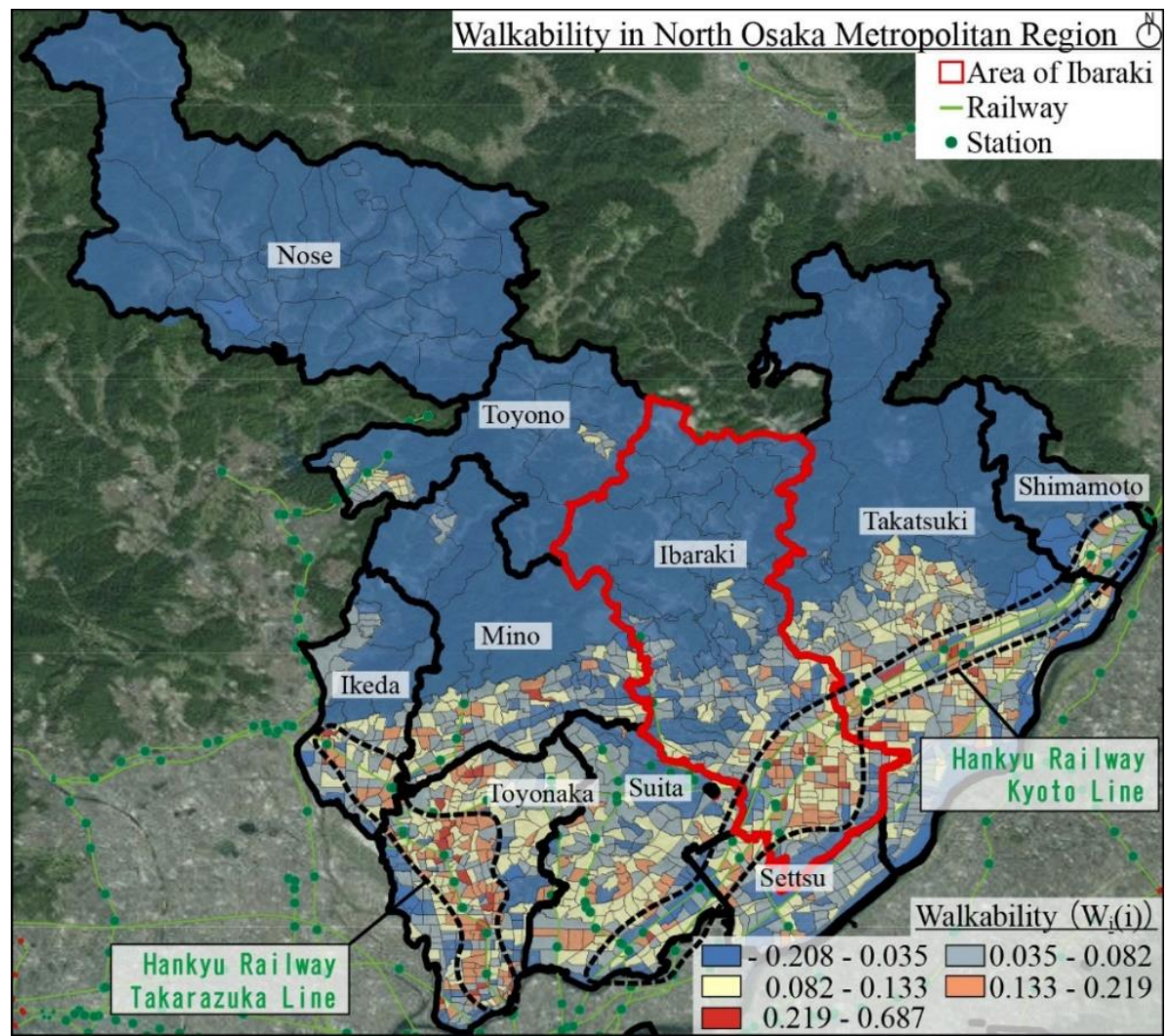

Figure 7. Evaluation on walkability of each city block in Northern Osaka Metropolitan Area

Next, the average $\mathrm{W}_{\mathrm{i}}(\mathrm{i})$ of each residential cluster in the cities is calculated (Figure 8). Moreover, the mean ("Mw") and standard deviation ("SDw") of $\mathrm{W}_{\mathrm{i}}(\mathrm{i})$ are analysed for each residential cluster.

Figure 8 shows that $\mathrm{W}_{\mathrm{i}}(\mathrm{i})$ in sprawl areas tends to be high and differs on each city block $(\mathrm{Mw}(\mathrm{Sp})=0.081 / \mathrm{SDw}(\mathrm{Sp})=0.053)$. Also, Figure 8 suggests that $\mathrm{W}_{\mathrm{i}}(\mathrm{i})$ in suburban areas tends to be low, and in public housing areas tends to be high $(\mathrm{Mw}(\mathrm{Su})=0.076 / \mathrm{SDw}(\mathrm{Su})=0.042)$.

As a result, this section suggests that $\mathrm{W}_{\mathrm{i}}(\mathrm{i})$ in sprawl areas and public housing areas may be important for visualizing the average of $\mathrm{W}_{\mathrm{i}}(\mathrm{i})$. 


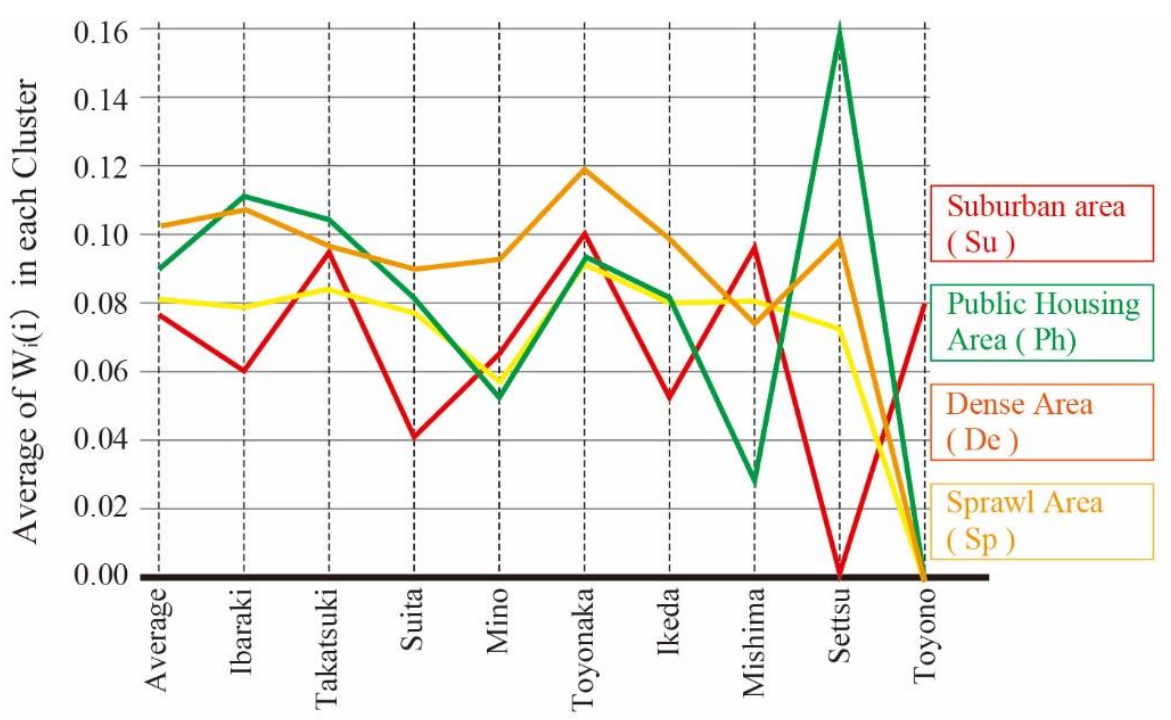

Figure 8 . Average $\mathrm{W}_{\mathrm{i}}(\mathrm{i})$ of residential clusters in the cities.

\subsubsection{Future population decline of high walkability areas}

Section 3.4.2 aims to calculate the future population decline in high walkability areas because Sections 2.3 and 3.3 suggest an association between $\mathrm{W}_{\mathrm{i}}(\mathrm{i})$ and future population decline through resident clusters.

For the purposes of this research, "walkable area" is defined as continuous city blocks with $\mathrm{W}_{\mathrm{i}}(\mathrm{i}) \geqq 0.1333$, which are indicated as having high walkability, shown as red in the legend of Figure 7. The walkable area of each city was calculated by $\mathrm{D}_{2035}$ (Figure 9 ), and a regression line was calculated for each city.

Figure 9 shows that the walkable areas have a positive correlation with $\mathrm{D}_{2035}$ in Ibaraki city and Takatsuki city. On the other hands, Figure 9 also shows a negative correlation with $\mathrm{D}_{2035}$ in Toyonaka City and Ikeda City. The results suggest that the walkable areas indicate the characteristics of population decline in each city.

As a result, Section 3 developed a walkability indicator. Moreover, the findings suggest that the walkability indicator is effective for visualizing the characteristics of population decline in each city.

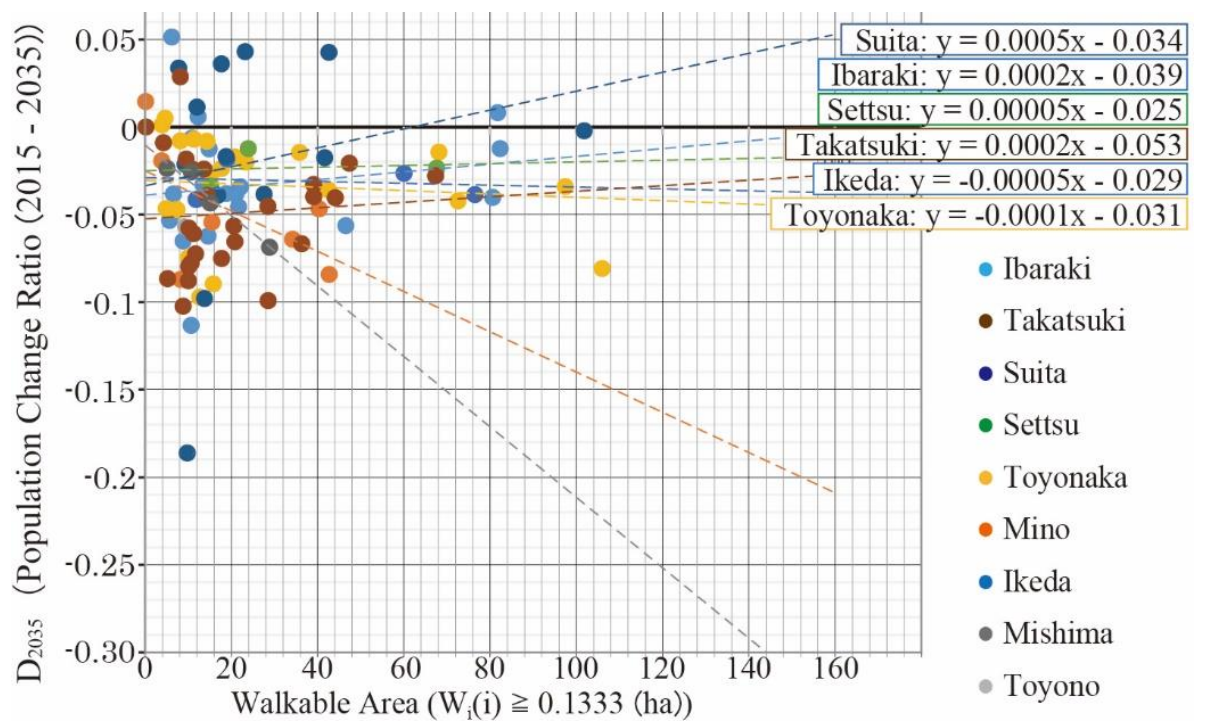

Figure 9. Future population decline of high walkability areas. 


\section{EXAMINATION OF VALIDITY AND EFFECTIVENESS OF THE INDICATOR BY QUESTIONNAIRE}

\subsection{Questionnaire Survey for Ibaraki City}

Section 4 aims to examine the validity and effectiveness of the walkability indicator at a regional level evaluation. A questionnaire survey about regional evaluation was conducted. 3,000 residents who live in urbanized areas of Ibaraki City in Northern Osaka Metropolitan Area participated in the survey. The area targeted for the analyses was Ibaraki City in Northern Osaka Metropolitan areas whereby the validity and effectiveness of large walkable areas in Figure 7 and low $\mathrm{D}_{2035}$ in Figure 5 are examined.

Section 4.1 shows a summary of the survey (Table 5). Table 5 shows that the survey received useful answers concerning the effective response rate. 898 people responded to the survey showing a $28.8 \%$ effective response rate. The sampling method was a layered two-stage random sampling method and the survey distribution method was by mail. Questionnaire content ranged from attributes of the respondents to evaluation of attractiveness in Ibaraki City. Table 5 shows that the survey asked about the city block where the respondent lived, to analyse any correlation with $\mathrm{W}_{\mathrm{i}}(\mathrm{i})$.

Table 5. Basic data from questionnaire survey

\begin{tabular}{|c|c|}
\hline \multirow{3}{*}{$\begin{array}{l}\text { Distribution / Responses（N) } \\
\text { Effective Response Rate (\%) } \\
\text { Sampling Method }\end{array}$} & $898 / 3,000$ people responded \\
\hline & $28.80 \%$ \\
\hline & $\begin{array}{l}\text { Layered two-stage random sampling method } \\
\text { Respondent's Residential Area } \times \text { Age } \\
\text { (Hilly area: Another area }=11: 16) \\
(20 \sim 39: 40 \sim 59: 60 \sim=4: 3: 2)\end{array}$ \\
\hline $\begin{array}{r}\text { Day of Distribution - Collection } \\
\text { Survey Method }\end{array}$ & $\begin{array}{l}2017 / 12 / 10 \sim 12 / 26 \\
\text { Mail }\end{array}$ \\
\hline $\begin{array}{l}\text { Respondents' Sex (\%) } \\
\text { Respondents' Age (\%) }\end{array}$ & $\begin{array}{l}\text { Male: } 40 \% \text { / Female: } 52 \% \text { / Unknown: } 8 \% \\
\text { 18-19: } 2 \% \text { / 20-29: } 12 \% \text { / 30-39: } 16 \% \text { / 40-49: } 16 \% \\
\text { / 50-59: } 18 \% \text { / 60-69: 11\% / 70-79: } 17 \% \\
\text { / over 80: } 7 \% \text { / Unknown: } 1 \% \text {. }\end{array}$ \\
\hline Contents of the Questionnaire & $\begin{array}{l}\text { 1. Attributes of the Respondent } \\
\text { 2. Intention to Live in the Residential Area } \\
\text { 3. Evaluation of Living Environment } \\
\text { 4. Evaluation of Town Plans for Walking or Cycling. } \\
\text { 5. Evaluation of Attractiveness in Ibaraki City. }\end{array}$ \\
\hline
\end{tabular}

\subsection{Validity of the Walkability Indicator from the Regional Evaluations}

\subsubsection{Regional attractiveness related to $W_{i}(i)$}

The effectiveness of the walkability indicator was verified for visualizing the characteristics of population decline in each city in Section 3.3. In addition to the results, Section 4.2 aims to clarify the validity of the walkability indicator from the regional evaluation following two steps. As a first step, Section 4.2.1 aims to reveal regional attractiveness as related to walkability $\mathrm{W}_{\mathrm{i}}(\mathrm{i})$. The methods used in this section were morphological analysis and logistic regression analysis.

First, this questionnaire asked an open-ended question: "What do you think is attractive in Ibaraki City?". The results were meaningful because there were 481 answers and 1,513 overlapping words. Morphological analysis was 
performed to draw a co-occurrence network (Figure 10). Figure 10 shows that attractiveness can be broken down into clear reasoning, for example, "The city has good access to Osaka and Kyoto," and so on.

Next, a co-occurrence network of each residential cluster was drawn (Figure 11). Figure 11 shows that the sprawl area has many attractive features common with other residential areas, for example, "nature" and "convenience." This result may suggest that the attractions of sprawl areas are shared with other residential clusters.

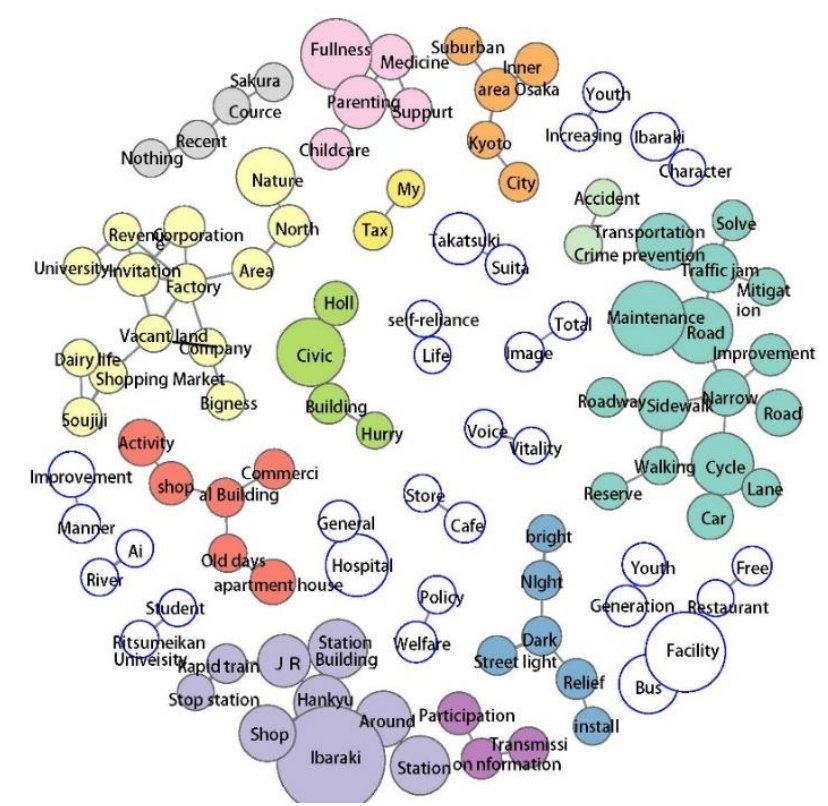

Figure 10. Co-occurrence network of Attractiveness in Ibaraki City (Threshold $=5 /$ Jaccard coefficient $\geqq 0.12$ )

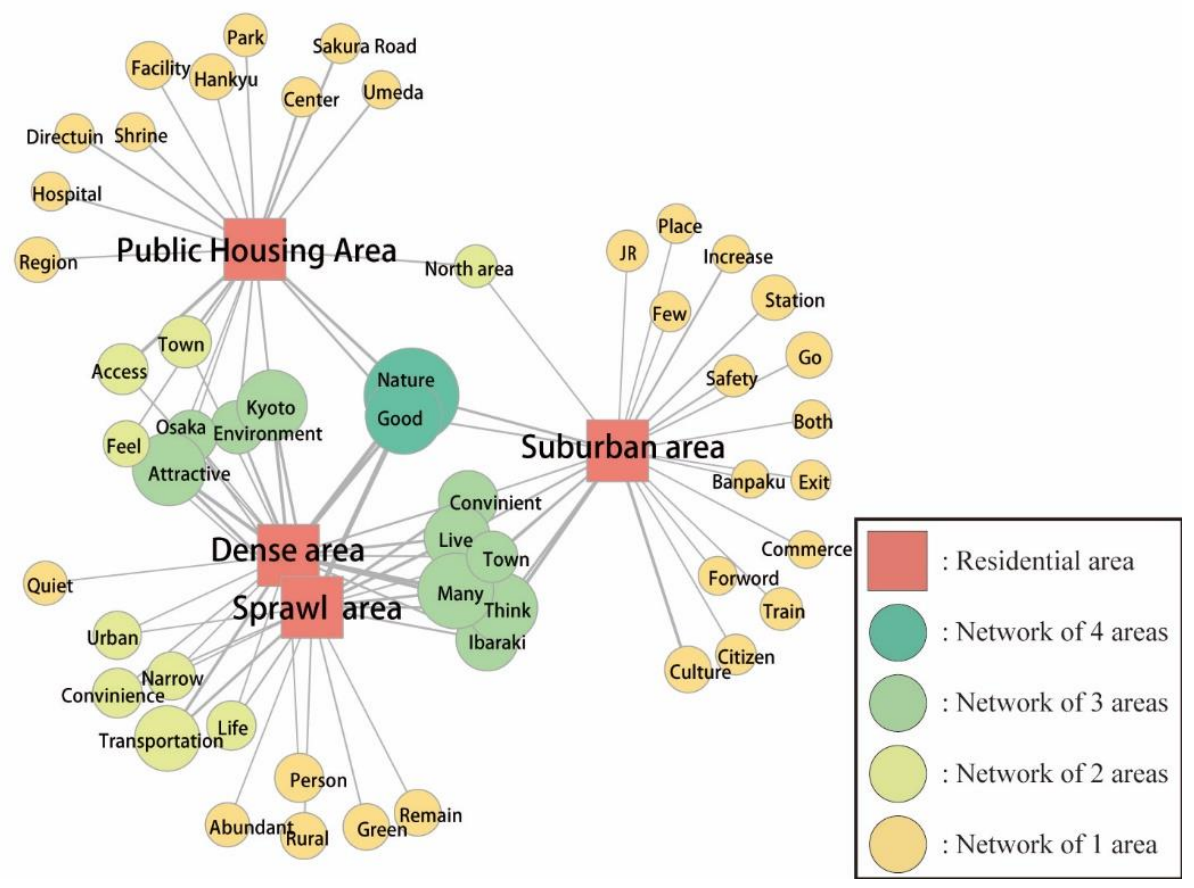

Figure 11. Co-occurrence network of Attractiveness in each cluster (Threshold $=5 /$ Jaccard coefficient $\geqq 0.23$ )

Second, this section aimed to clarify the attractions that are influenced by $\mathrm{W}_{\mathrm{i}}(\mathrm{i})$. Thus, the questionnaire asked multiple-answer questions, such as "What do you think is attractive in your residential area?" The question item 
is related to attractiveness in Figures 10 and 11. Next, a logistic regression analysis was conducted by setting response variables as the answers and the explanatory variable as $\mathrm{W}_{\mathrm{i}}(\mathrm{i})$ of respondents' residential areas (Table 6).

Table 6 shows that $\mathrm{W}_{\mathrm{i}}(\mathrm{i})$ strongly affects attractiveness: "You can live daily life by walking or cycling" ( $B=9.94)$. Therefore, the result supports the result of the network in Figure 11. Moreover, Table 6 shows that the walkability indicator is correlated with daily life through walking or cycling.

Table 6. Regional attractiveness related to $\mathrm{W}_{\mathrm{i}}(\mathrm{i})$ (Notation of answers only adapted stepwise)

\begin{tabular}{rcrrrr}
\hline $\mathbf{N}$ & Attractiveness of Residential Area & B & SE & p & OR \\
\hline 659 & You can conduct daily life by walking or cycling & 9.64 & 1.81 & 0 & 15312 \\
& & 0.19 & 0.2 & 0.32 & 1.21 \\
\hline 81 & There are many favourite shops and cafes & & & & \\
\hline 150 & You have many interactions with neighbours & & & & \\
\hline 41 & You can transmit information about local activities & 8.66 & 1.74 & 0 & 5748 \\
& & 0.21 & 0.19 & 0.27 & 1.23 \\
\hline 645 & You have good access to Osaka or Kyoto & -5.93 & 1.46 & 0 & 0 \\
& & 0.23 & 0.17 & 0.18 & 1.26 \\
\hline 341 & You have a natural environment & 3.89 & 1.79 & 0.03 & 48.91 \\
& & -2.08 & 0.23 & 0 & 0.13 \\
\hline 139 & You have history and nature in your area & & & & \\
\hline 86 & There are sufficient educational facilities & & & & \\
\hline 204 & There are sufficient hospitals and clinics & -1.61 & 0.2 & 0.01 & 60.14 \\
& & & & 0.2 \\
\hline 49 & There are sufficient nursing and care facilities & & & \\
\hline 83 & There are workplaces nearby
\end{tabular}

Notes: The upper cell shows the "variables", the lower cell shows the "constants."

B: Regression Coefficient; SE: Standard Error; p: Significance Probability; OR: Odds Ratio

\subsubsection{Relationship between walkable areas and attractive roads}

Section 4.2.2 aims to reveal the association between walkable areas and attractive roads for walking or cycling. That is because Section 4.2.1 clarified that there is a relationship between $\mathrm{W}_{\mathrm{i}}(\mathrm{i})$ and daily life through walking or cycling.

Thus, the questionnaire asked an open-ended question: "Where are the attractive roads in your residential area?" Next, the roads on $\mathrm{W}_{\mathrm{i}}(\mathrm{i})$ were added to Figure 7 (Figure 12)

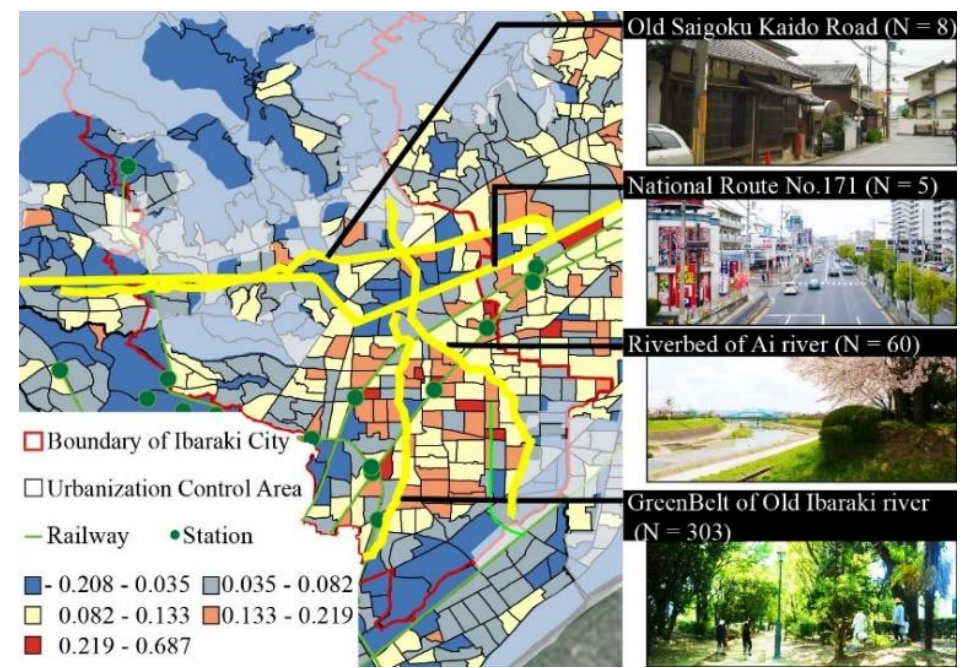

Figure 12. Relationship between walkable areas and attractive roads for walking or cycling. 
Figure 12 shows that the attractive roads for walking or cycling, for example, the Green Belt of Old Ibaraki river and the riverbed of the Ai river, create boundaries between high and low walkable areas. The results may suggest that $\mathrm{W}_{\mathrm{i}}(\mathrm{i})$ influences daily behaviour by being able to walk or cycle.

\subsubsection{Daily behaviours that are affected by $W_{i}(i)$}

Section 4.2.3 aims to clarify the influence on means of daily movement by $\mathrm{W}_{\mathrm{i}}(\mathrm{i})$ as Sections 4.2.1 and 4.2.2 clarified the relationship between walkability and daily life through walking or cycling.

The questionnaire asked about areas where respondents went (residential area/central city area/out of Ibaraki City /other areas) by different means (walking or cycling/bus or train/car) in daily life. Next, this section performed a logistic regression analysis by setting response variables as the answers and explanatory variables as $\mathrm{W}_{\mathrm{i}}(\mathrm{i})$ of respondents' residential areas (Table 7).

Table 7 shows that $\mathrm{W}_{\mathrm{i}}(\mathrm{i})$ influences positively on daily behaviours of "daily shopping" and "natural facilities" by promoting walking or cycling to go to "residential areas". Besides this, the Figure shows that $\mathrm{W}_{\mathrm{i}}(\mathrm{i})$ influences positively on daily behaviours of "nursing and care facilities" and "nursery facilities" by promoting walking or cycling to go to "central city areas". As a result, the validity of the walkability indicator is clarified by residents' regional evaluations and their daily behaviour of walking or cycling.

Table 7. Daily behaviours that are affected by $\mathrm{W}_{\mathrm{i}}(\mathrm{i})$ (Notation of answers only adapted stepwise)

\begin{tabular}{|c|c|c|c|c|c|c|c|}
\hline & Daily Behaviours & Movement Area & & B & SE & p & OR \\
\hline \multirow{24}{*}{ 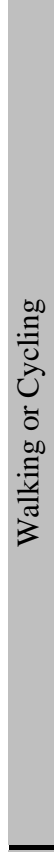 } & \multirow{4}{*}{ Daily Shopping- } & \multirow{2}{*}{\multicolumn{2}{|c|}{ Residential Area 483}} & 9.74 & 1.75 & 0 & 16965 \\
\hline & & & & -0.39 & 0.2 & 0.05 & 0.68 \\
\hline & & \multirow{2}{*}{$\begin{array}{c}\text { Central City } \\
\text { Area }\end{array}$} & \multirow[t]{2}{*}{317} & 8.39 & 1.58 & 0 & 4382 \\
\hline & & & & -1.18 & 0.19 & 0 & 0.31 \\
\hline & \multirow{2}{*}{$\begin{array}{l}\text { Multi-generation } \\
\text { Interchange Facilities }\end{array}$} & \multirow{2}{*}{$\begin{array}{c}\text { Central City } \\
\text { Area } \\
\end{array}$} & \multirow[t]{2}{*}{61} & 8.15 & 2.47 & 0 & 3465 \\
\hline & & & & -3.35 & 0.35 & 0 & 0.04 \\
\hline & \multirow{4}{*}{ Hospitals and Clinics- } & \multirow{2}{*}{ Residential Area } & \multirow[t]{2}{*}{381} & 6.80 & 1.56 & 0 & 894 \\
\hline & & & & -0.66 & 0.19 & 0 & 0.52 \\
\hline & & Central City & 244 & 10.21 & 1.67 & 0 & 27225 \\
\hline & & Area & & -1.85 & 0.21 & 0 & 0.16 \\
\hline & \multirow{2}{*}{$\begin{array}{r}\text { Nursing and Care } \\
\text { Facilities } \\
\end{array}$} & Central City & 9 & 13.74 & 5.46 & 0.01 & 923166 \\
\hline & & Area & & -6.16 & 0.9 & 0 & 0 \\
\hline & \multirow{2}{*}{ Nursery Facilities } & Central City & 35 & 10.82 & 3.08 & 0 & 50184 \\
\hline & & Area & & -4.31 & 0.46 & 0 & 0.01 \\
\hline & \multirow{4}{*}{$\begin{array}{r}\text { Education and Culture } \\
\text { Facilities }\end{array}$} & Residential Area & 146 & 5.68 & 1.81 & 0 & 294 \\
\hline & & К. & & -2.04 & 0.24 & 0 & 0.13 \\
\hline & & Central City & 108 & 8.13 & 2.01 & 0 & 3380 \\
\hline & & Area & & -2.70 & 0.27 & 0 & 0.07 \\
\hline & \multirow{2}{*}{ Public Facilities } & Central City & 101 & 9.40 & 2.06 & 0 & 12122 \\
\hline & & Area & & -2.93 & 0.28 & 0 & 0.05 \\
\hline & \multirow{4}{*}{ Natural Facilities } & Residential Area & 284 & 9.61 & 8 & 0.01 & 58 \\
\hline & & - & & -0.91 & 0.19 & 0 & $\begin{array}{r}0.4 \\
-\ldots-.3\end{array}$ \\
\hline & & Central city & 130 & 8.52 & 1.89 & 0 & 5010 \\
\hline & & area & & -2.51 & 0.25 & 0 & 0.08 \\
\hline \multirow{8}{*}{ 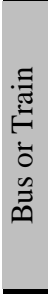 } & \multirow{2}{*}{$\begin{array}{r}\text { Multi-generation } \\
\text { Interchange Facilities }\end{array}$} & \multirow{2}{*}{ Residential Area } & 11 & -15.1 & 7.1 & 0.03 & 4.54 \\
\hline & & & & -2.84 & 0.64 & 0 & 19.61 \\
\hline & \multirow{4}{*}{ Nursing and Care Facilities } & \multirow{2}{*}{ Residential Area } & \multirow[t]{2}{*}{11} & -20.4 & 6.97 & 0 & 8.6 \\
\hline & & & & -2.35 & 0.57 & 0 & 17.1 \\
\hline & & Out of & 55 & 5.41 & 2.64 & 0.04 & 4.18 \\
\hline & & Ibaraki City & & -3.14 & 0.36 & 0 & 78.18 \\
\hline & \multirow{2}{*}{ Public Facilities } & \multirow{2}{*}{$\begin{array}{c}\text { Out of } \\
\text { Ibaraki City }\end{array}$} & 13 & 11.01 & 4.75 & 0.02 & 5.37 \\
\hline & & & & -5.38 & 0.73 & 0 & 54.06 \\
\hline \multirow{5}{*}{ Uี } & \multirow{5}{*}{ Daily Shopping- } & Residential Area & 78 & -8.10 & 2.59 & 0.01 & 6.73 \\
\hline & & & & -1.27 & 0.28 & 0 & 26.79 \\
\hline & & Out of & 75 & -4.59 & 2.24 & 0 & 10.59 \\
\hline & & Ibaraki City & & -1.34 & 0.25 & 0 & 21.98 \\
\hline & & & & -9.81 & 3.78 & 0 & 9.1 \\
\hline
\end{tabular}




\begin{tabular}{|c|c|c|c|c|c|c|}
\hline $\begin{array}{l}\text { Multi-generation } \\
\text { Interchange Facilities }\end{array}$ & Residential Area & 37 & -1.99 & 0.38 & 0 & 24.03 \\
\hline \multirow{4}{*}{ Hospitals and Clinics } & \multirow{2}{*}{\multicolumn{2}{|c|}{ Residential Area 56}} & -10.1 & 3.11 & 0.01 & 6.73 \\
\hline & & & -1.49 & 0.32 & 0 & 26.79 \\
\hline & Central city & 44 & -10.3 & 3.42 & 0 & 10.59 \\
\hline & area & & -1.69 & 0.35 & 0 & 21.98 \\
\hline
\end{tabular}

Notes: The upper cell shows the "variables" / the lower cell shows the "constants."

B: Regression Coefficient; SE: Standard Error; p: Significance Probability; OR: Odds Ratio

\subsection{Effectiveness of the Walkability Indicator}

Section 4.3 aims to confirm the effectiveness of the walkability indicator by clarifying the designs that improve $\mathrm{W}_{\mathrm{i}}(\mathrm{i})$ in each residence cluster, as Section 4.2 suggested that $\mathrm{W}_{\mathrm{i}}(\mathrm{i})$ positively influenced daily behaviour in walking and cycling.

Therefore, the questionnaire asked multiple-answer questions, such as "What kind of efforts are necessary to create walkable areas?". The components of this question consisted of indicators that were reviewed from Table 2. Next, this section quantified theory Type-I by setting response variables as $\mathrm{W}_{\mathrm{i}}(\mathrm{i})$ of respondents' residential area and the explanatory variables as the answers.

Table 8. Designs that influence $\mathrm{W}_{\mathrm{i}}(\mathrm{i})$ in each residential area (Notation of answers only adapted stepwise)

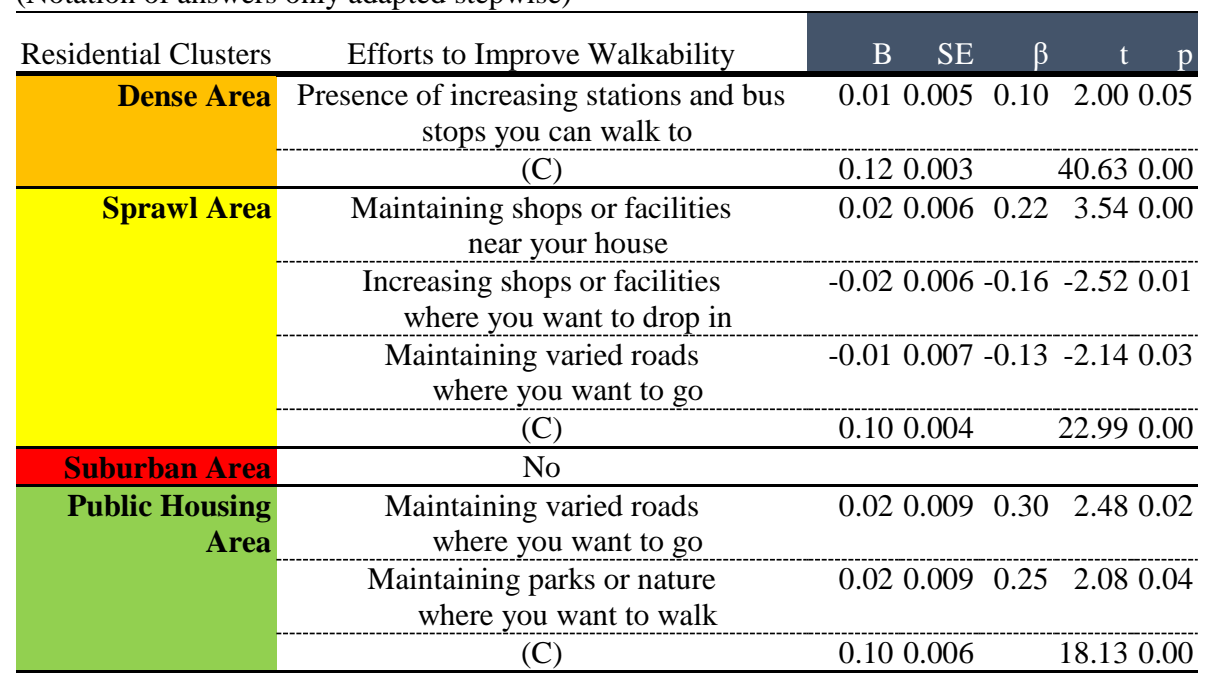

Notes: B: Regression Coefficient; SE: Standard Error; p: Significance Probability; OR: Odds Ratio; 95\% CI: 95\% Confidence Interval (Max., Min.)

Table 8 shows that what is necessary differs for each residential cluster. In particular, $\mathrm{W}_{\mathrm{i}}(\mathrm{i})$ in dense areas is positively influenced by the "Presence of bus stops or stations which you can go to by walking" $(\mathrm{B}=0.011)$.

On the other hand, $\mathrm{W}_{\mathrm{i}}(\mathrm{i})$ in sprawl areas is positively influenced by "Maintaining shops or facilities near your house" $(\mathrm{B}=0.023)$, and is negatively influenced by "Increasing shops or facilities near your house" $(\mathrm{B}=$ -0.015). The results suggest that "maintenance" facilities have a positive influence on $\mathrm{W}_{\mathrm{i}}(\mathrm{i})$ rather than "increasing" them in sprawl areas.

Unlike dense areas and sprawl areas, $\mathrm{W}_{\mathrm{i}}(\mathrm{i})$ in suburban areas is not influenced by design. The analysis suggests that suburban areas in Ibaraki City cannot be designed from the perspective of walkability.

Finally, $\mathrm{W}_{\mathrm{i}}(\mathrm{i})$ in public housing areas is positively influenced by design that involves "Maintaining variable roads where you want to go" $(\mathrm{B}=0.023)$, and the design of "Maintaining parks or nature where you want to walk" $(\mathrm{B}=$ 
0.019). The data show that public housing areas are positively influenced by the residential environment.

As a result, this section suggests that $\mathrm{W}_{\mathrm{i}}(\mathrm{i})$ in sprawl areas and public housing areas is influenced not only by the design of "the functional location of the regional facilities" but also by the design of the "regional environment." Moreover, this clarifies the effectiveness of the walkability indicator by clarifying the designs that improve $\mathrm{W}_{\mathrm{i}}(\mathrm{i})$.

\section{CONCLUSION}

This paper develops a walkability indicator for visualizing smart shrinking, which considers design methods intended to satisfy residents' living needs, even though the population is gradually declining. The walkability indicator is identified by the validity and effectiveness according to the regional-level evaluation in the case of the Northern Osaka Metropolitan Area. The following four points are concluded:

(1) First, this study classified the population decline of each residential cluster in the Northern Osaka Metropolitan Area. The methods were urban factorial ecological analysis with Japanese census data and GIS analysis using a "Future population prediction system in Japan". By this analysis, ten residential clusters were clarified: dense areas, sprawl areas, suburban areas, and public housing areas, and so on. Moreover, it suggests that the population decline in sprawl areas indicates the regional characteristics of cities.

(2) Second, this study modelled the walkability indicator. For the modelling, this study defined the concept of walkability as "residential environment that promotes walking or cycling in safety, with comfort, and the attractions of daily life". From this definition, the walkability indicator was developed, composed of four factors: household density, convenience of facilities, road connectivity, and regional safety. They were chosen because local governments obtain the data and analyse the walkability by GIS survey. Moreover, they were highly reliable factors specified by many indicators. The indicator was analysed for validity by SEM, showing how the indicator affects future population growth or decline.

(3) Third, this study analysed the locational characteristics of high walkability areas. For the analysis, the walkability indicator was formulated to evaluate the $\mathrm{W}_{\mathrm{i}}(\mathrm{i})$, which is the walkability of each residential area. Based on the $\mathrm{W}_{\mathrm{i}}(\mathrm{i}), \mathrm{W}_{\mathrm{i}}(\mathrm{i})$ in the Northern Osaka Metropolitan Area were mapped. As a result, it was found that high walkability areas have accumulated in other areas and $\mathrm{W}_{\mathrm{i}}(\mathrm{i})$ is influenced not only by geography but also by residential clusters. Moreover, these findings suggest that $\mathrm{W}_{\mathrm{i}}(\mathrm{i})$ in sprawl areas and public housing areas is important to future population changes in cities.

(4) Finally, this study examined the validity and effectiveness of the walkability indicator using a questionnaire survey about regional evaluation for the urbanized area in Ibaraki City. The results clarify the validity of the walkability indicator using residents' regional evaluations and daily behaviours of walking or cycling. Moreover, they clarified the effectiveness of the indicator by explicating the designs that improve $\mathrm{W}_{\mathrm{i}}(\mathrm{i})$.

Japanese local governments in metropolitan areas will face reduced tax revenue due to population decline. Therefore, the central government will have problems pertaining to future investment because sprawl areas are required to renovate sufficient infrastructure. However, for the local government, the walkability indicator allows the central government to request information on the needs for renovating infrastructure. 
Evaluating the residential areas using the walkability indicator may enable evaluation of the existing infrastructure of sprawl areas from the viewpoints of regional evaluation. That suggests possibilities to plan policy for smart shrinking. That is, for maintaining the sustainability of sprawl areas in realistic ways. These results are useful not only for Japan but also for other countries where large areas of small-sprawl face a decline in population.

\section{ACKNOWLEDGEMENTS}

We are deeply grateful for the support of the "Urban Development Department of Ibaraki City Government (Local Government in Northern Osaka Metropolitan Area)" and the "Architects, Regional Planners \& Associates, Kyoto (Corporation of Urban Planning Consultants)".

\section{NOTES}

[1] Data source: Geospatial Information Authority of Japan, http://maps.gsi.go.jp

[2] Data source: E Stat, Census Data in 2010, http://www.estat.go.jp/SG1/estat/NewList.do?tid=000001039448

49 indicators are below.

Population by age / Population five years ago / Household family population / Households by type of housing construction / Number of households by type of residence and total area / Number of employed people by occupation / Number of workers and students by transportation method

[3] We use the software "Arc GIS"

[4] Data source: INOUE T, The web system of small area population projections for the whole of Japan, http://aguecon.maps.arcgis.com/apps/webappviewer/index.html?id=f9a6b13f97bc4906 9035 ef3793150950

[5] Data source: e Stat, Census Data in 2010, http://www.estat.go.jp/SG1/estat/NewList.do?tid=000001039448

[6] Data source: I town page, https://itp.ne.jp/?rf=1

[7] Data source: National Land Numerical Information Download Service, Data Download, http://nlftp.mlit.go.jp/ksj-e/gml/gml_datalist.html

[8] Data source: ESRI, ArcGIS Geo Suite road networks (Osaka prefectural version).

[9] Data source: Osaka Prefectural Police, Crime occurrence map (January - December, 2016), http://www.map.police.pref.osaka.jp/Public/MapMain.aspx?pcode=202

[10] Data source: Osaka Prefectural Police, Traffic accident occurrence map of your town (January - December, 2015), https://www.police.pref.osaka.jp/03kotsu/kensu/map/lastyear/02/jiko/02_06ibatagihoku bu_1_1.html

[11] We use the software "SPSS Amos 24.0"

[12] We use the software "KH Coder (http://khc.sourceforge.net/en/)" \& "R (https://www.rproject.org/)"

\section{REFERENCES}

AtKisson, A. (1996). "Developing Indicators of Sustainable Community: Lessons from Sustainable Seattle". Environmental Impact Assessment Review, 16(4), 337-350. doi: https://doi.org/10.1016/S0195-9255(96)00025-X.

Brownson, R. C., Hoehner, C. M., Day, K., Forsyth, A., \& Sallis, J. F. (2009). "Measuring the Built Environment for Physical Activity: State of the Science". American journal of preventive medicine, $36(4 \quad$ Suppl), $99-123 . \quad$ doi: https://doi.org/10.1016/j.amepre.2009.01.005. 
Buhnik, S. (2010). "From Shrinking Cities to Toshi No Shukushō: Identifying Patterns of Urban Shrinkage in the Osaka Metropolitan Area". Berkeley Planning Journal, 23(1), 132 - 155. doi: https://doi.org/10.5070/BP323111434.

Cerin, E., Saelens, B. E., Sallis, J. F., \& Frank, L. D. (2006). "Neighborhood Environment Walkability Scale: Validity and Development of a Short Form". Medicine and Science in Sports and Exercise, 38(9), 1682-1691. doi: https://doi.org/10.1249/01.mss.0000227639.83607.4d.

Cervero, R., \& Kockelman, K. (1997). "Travel Demand and the 3ds: Density, Diversity, and Design". Transportation Research Part D: Transport and Environment, 2(3), 199-219. doi: https://doi.org/10.1016/S1361-9209(97)00009-6.

Frank, L. D., Sallis, J. F., Conway, T. L., Chapman, J. E., Saelens, B. E., \& Bachman, W. (2006). "Many Pathways from Land Use to Health: Associations between Neighborhood Walkability and Active Transportation, Body Mass Index, and Air Quality". Journal of the American Planning Association, 72(1), 75-87. doi: https://doi.org/10.1080/01944360608976725.

Frank, L. D., Schmid, T. L., Sallis, J. F., Chapman, J., \& Saelens, B. E. (2005). "Linking Objectively Measured Physical Activity with Objectively Measured Urban Form: Findings from Smartraq". American Journal of Preventive Medicine, 28(2, Supplement 2), 117-125. doi: https://doi.org/10.1016/j.amepre.2004.11.001.

Hanibuchi, T., Kondo, K., Nakaya, T., Shirai, K., Hirai, H., \& Kawachi, I. (2012). "Does Walkable Mean Sociable? Neighborhood Determinants of Social Capital among Older Adults in Japan". Health Place, 18(2), 229-239. doi: https://doi.org/10.1016/j.healthplace.2011.09.015.

Hattori, K., Kaido, K., \& Matsuyuki, M. (2017). "The Development of Urban Shrinkage Discourse and Policy Response in Japan". Cities, 69, 124-132. doi: https://doi.org/10.1016/j.cities.2017.02.011.

Hibata, Y., Asami, Y., \& Endo, K. (2009). "Tokyo Model as Re-Design the Densely Built Areas". Seibunsya.

Hollander, J. B., \& Németh, J. (2011). "The Bounds of Smart Decline: A Foundational Theory for Planning Shrinking Cities". Housing Policy Debate, 21(3), 349-367. doi: https://doi.org/10.1080/10511482.2011.585164.

Hollander, J. B., Pallagst, K., Schwarz, T., \& Popper, F. J. (2009). "Planning Shrinking Cities". Progress in planning, 72(4), 223-232.

Inoue, S., Ohya, Y., Odagiri, Y., Takamiya, T., Ishii, K., Lee, J. S., \& Shimomitsu, T. (2009). "Reliability of the Abbreviated Neighborhood Environment Walkability Scale Japanese Version". Japanese Journal of Physical Fitness and Sports Medicine, 58(4), 453-462. doi: https://doi.org/10.7600/jspfsm.58.453.

Inoue, T. (2015). "Development and Publication in Web of "the Web System of Small Area Population Projection for the Whole Japan"". Research Abstracts on Spatial Information Science CSIS DAYS 2015, 29.

Japanese MIC (Ministry of Internal Affairs and Communications). (2016). "White Paper on Local Public Finance". Retrieved from http://www.soumu.go.jp/iken/zaisei/28data/chihouzaisei 2016 en.pdf

Japanese MLIT (Ministry of Land, Infrastructure and Transport). (2011). "Promotion of Disaster Prevention and Reconstruction from the Great East Japan Earthquake". Retrieved from http://www.mlit.go.jp/common/000996975.pdf.

Japanese MLIT (Ministry of Land, Infrastructure and Transport). (2015). "National Spatial Strategy (National Plan)". Retrieved from http://www.mlit.go.jp/common/001127196.pdf.

Kurokawa, T., Taniguchi, M., Hashimoto, H., \& Ishida, H. (1995). "Cost of Infrastructure Improvement on Sprawl Area: Costsaving Effect by Early Action". Journal of the City Planning Institute of Japan, 30, 121-126.

Mitani, T., \& Yamanaka, H. (1992). "An Analysis of Build-up, Effects Caused by Collector Streets in Sprawl Development Areas". Journal of the City Planning Institute of Japan, 27, 205-210.

Miwa, K., Yasuda, C., \& Suekane, S. (1996). "A Study on the Population and Household Changes and Housing Improvement of Housing Estate - Analysis of Aging of Inhabitant and Improvement of Detached House District in Kobe City". Journal of the City Planning Institute of Japan, 31, 463-468.

NIPSSR Tokyo (National Institute of Population and Social Security Research Tokyo). (2013). "Regional Population Projections for Japan: 2010-2040". Population Research Series, 330.

Simpson, J. A., \& Weiner, E. S. C. (1989). The Oxford English Dictionary Second Edition Volume Xix. Oxford: Clarendon Press 
Sorensen, A. (1999). "Land Readjustment, Urban Planning and Urban Sprawl in the Tokyo Metropolitan Area". Urban Studies, 36(13), 2333-2360. doi: https://doi.org/10.1080/0042098992458.

Sorensen, A. (2001). "Building Suburbs in Japan". Town Planning Review, 72(3), 247-274. doi: https://doi.org/10.3828/tpr.2001.72.3.247.

Southworth, M. (2005). "Designing the Walkable City". Journal of Urban Planning and Development, 131(4), 246-257. doi: https://doi.org/10.1061/(ASCE)07339488(2005)131:4(246).

Suzuki, Y., Kachi, N., Togawa, T., Kato, H., \& Hayashi, Y. (2009). "Urban Sustainability Evaluation System “Surquas ” (Smart Urban Area Relocation Model for Sustainable Quality Stock) ". Proceedings of The 12th World Conference on Transport Research, Lisbon.

Tsukaguchi, H. (1991). "Planning of Residential Streets in Urban Residential Areas". Journal of the City Planning Institute of Japan, 26, 235-240.

Wiechmann, T., \& Pallagst, K. M. (2012). "Urban Shrinkage in Germany and the USA: A Comparison of Transformation Patterns and Local Strategies". International Journal of Urban and Regional Research, 36(2), 261-280. doi: https://doi.org/10.1111/j.14682427.2011.01095.x. 